\title{
Title:
}

\section{Assessing the Quality of Footwear Marks Recovered from Simulated Graves}

\author{
Madeleine Stephens ${ }^{\mathrm{a}}$ David Errickson ${ }^{\mathrm{a}}$ Stephanie B. Giles ${ }^{\mathrm{a}}$ Trevor J. Ringrose ${ }^{\mathrm{b}}$
}

a Cranfield Forensic Institute, Cranfield University, Defence Academy of the United Kingdom, Shrivenham, SN6 8LA, UK 


\section{Abstract}

Footwear marks are one of the most frequently encountered evidence types recovered from a crime scene and can provide valuable scene intelligence regarding potential suspects. It has been acknowledged that impressions of footwear and tools can be recovered from graves, but previous studies have only focused on tool mark recovery. This has led to a lack of published information regarding footwear mark recovery from graves. It is therefore important to demonstrate whether the recovery of footwear marks is feasible and, if so, under what conditions this can be achieved. To address recovery, this study, placed 60 three dimensional (3D) impressions of footwear marks within 60 simulated graves. This was done to assess time (1, 2, 4 months) and at known depths $(20,30$, $40 \mathrm{~cm}$ ). The footwear marks within the graves were covered with clothing or left uncovered. The shoe's design patterns were grouped and counted in a photographic comparison between the 3D footwear impressions, placed within the test-pits, and any recovered impressions. A grading system was adapted by the authors to score the quality of footwear impressions observed during recovery. The results demonstrate that the preservation and recovery of footwear impressions from graves is feasible.. The simulated graves covered with clothing showed better preservation of footwear impressions, but there was no clear evidence that time or depth had an effect. The authors note that careful consideration and vigilant excavation skills are needed when excavating graves which may bear potential footwear marks, as their recovery will lead to an increased amount of intelligence that can link suspects to homicide scenes.

\section{Keywords}

Excavation

Footwear Impression

Forensic Archaeology

Trace Evidence

\section{Introduction}

Within the United Kingdom, footwear marks and impressions are one of the most frequently encountered evidence types within a crime scene [1]. Footwear marks can be classified into two categories: two-dimensional (2D) marks and three-dimensional impressions (3D; Figure 1) [2]. A 3D impression is defined as the deforming of a soft surface, such as snow, soil or sand, from the impression of the footwear $[3,4,1]$. In the past, footwear marks have been underestimated as an evidence type, due to lack knowledge of forensic potential from first attending officers to the scene [5]. However, within the last decade there has been an increased acknowledgement of the high level of evidential value it holds, which can be 'as strong as conclusive' [6 p. 14]. The significance of footwear evidence is highly valuable because, unlike fingerprints, it is extremely difficult to reduce the contact of footwear within a crime scene [7]. Footwear evidence can offer valuable intelligence, such as providing information regarding the number of potential suspects at the scene and through pattern analysis can link crime scenes $[3,8,4]$. Impressions and marks recovered at the crime scene can be 
compared to control footwear prints obtained from the suspect in custody and provide evidence towards the presence of the footwear at a scene $[9,3]$.

Forensically significant footwear characteristics are located on the outer sole of footwear and contain class and individual characteristics [1]. Class characteristics include shape, size and design patterns, produced by the manufacturer; with over a thousand different designs on the market $[1,3,2]$. Unlike class characteristics, individual characteristics can be used for comparative purposes. Individual characteristics are distinctive to the footwear and normally fall into two categories: i) wear and ii) randomly acquired characteristics, such as damage $[10,11]$. The positive identification or exclusion of footwear marks is based on these distinctive characteristics, pattern, size and type of the footwear, by experienced footwear experts [6].

(A)

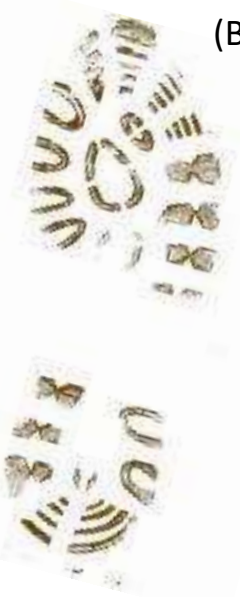

(B)

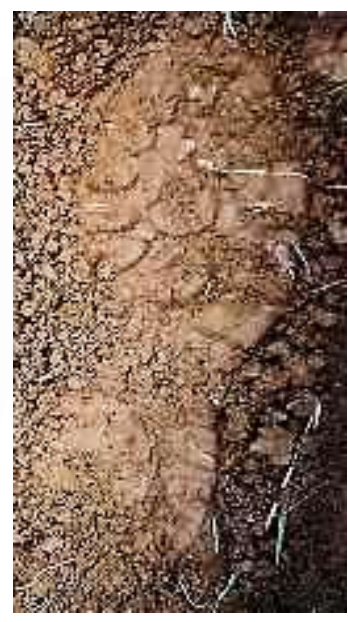

Figure 1. A) 2D Footwear Mark. (B) 3D Footwear Impression. The same footwear was used to create both marks.

Forensic archaeology, at its core, is 'the excavation and recovery of human remains and associated items from clandestine graves' [12 p. 19]. As this forensic discipline has developed, there is an increased understanding of what other potential evidence can be recovered from a grave dug into soil substrates. Trace and contact evidence (materials such as fibres, glass, soil and paint, fingerprints and footwear) can be transferred from an environment to a suspect or scene and are often sources of forensic relevance providing a link between the suspect and the scene $[2,13]$. Although there is a strong focus into the recovery of trace and impression evidence at grave sites which could have been transferred from perpetrator to the environment or victim [14], the presence of footwear impressions within graves has often been neglected within forensic archaeology.

Hunter and Cox [14] emphasise the possibility that footwear impressions can lie underneath human remains if the soil substrate is stable enough to preserve the impression. The substrate needs to be malleable enough to be deformed, but strong enough to retain the impression [14]. However, at present there is a significant lack of published studies into the feasibility of footwear marks being recovered from clandestine burial crime scenes. In relation to trace evidence recovered from graves, most studies have focused on tool marks and include, mechanical diggers and garden tools such as spades and mattocks. It is widely acknowledged that tool marks can be recovered from graves, with numerous studies and published forensic case work accounting for this $[15,16,17,18]$. 
The small number of publications which do mention footwear mark recovery within graves either outline the theory of recovery or simply mention that they have been found, but not to what extent or under which conditions $[19,15,14]$. There is very little published, with only one published photograph, of a footwear impression which has been recovered from a grave. This was published within Hunter \& Cox [14 p. 114] from a case connected with the Durham Constabulary. In this example the footwear impression was recovered from underneath the body, but no other contextual information regarding the recovery was documented. Similarly, DeFrance \& Payne's [20] study into the feasibility of recovering footwear marks within buried snow, showed that, with the right techniques, it was possible to recover buried footwear marks under snow. However, the substrate and conditions of DeFrance \& Payne's [20] study are very different to those associated with graves dug into soil substrates.

The conditions needed for the recovery of footwear marks within a grave are not widely discussed. However, Hunter and Cox [14], do outline that the preservation and recovery of these marks can be subject to variables such as the soil type, decomposition wetness and bioturbation occurring in shallow graves. The possible impact of grave depth on footwear mark recovery was also noted within Hochrein's [15] studies, where it was suggested that the increased depth of a grave could be affected by ground water activity and rodent disturbances, thus destroying any potential footwear marks. Previous studies into tool mark recovery have also shown a lack of knowledge into the effects of time on evidence preservation $[15,16]$.

This deficiency of published research into footwear recovery from soils within graves has led to the design of this study. The aim of this study is to assess the feasibility of recovering footwear marks from soil that have been placed within simulated graves. To assess the impact on recovery, three conditions were tested: the depth of the grave, the duration of burial and the presence of clothing covering the impressions. If footwear marks can be recovered from graves it could inform forensic excavation strategies and provide intelligence to assist in the identification of potential perpetrators.

\section{Material and Methods}

3D footwear impressions were left within simulated graves, consisting of loamy and clayey soils [21], for prolonged periods of time, at known depths, and either covered or uncovered with clothing to assess the quality of any recovered marks. To limit and for consistency, only one soil type was used within the investigation: a loamy and clayey soil. The footwear used to create the known footwear impressions within the study was a Vibram Vasque womens walking boot, UK size 5 (Figure 2). The sole pattern was selected due to the detailed tread pattern. 


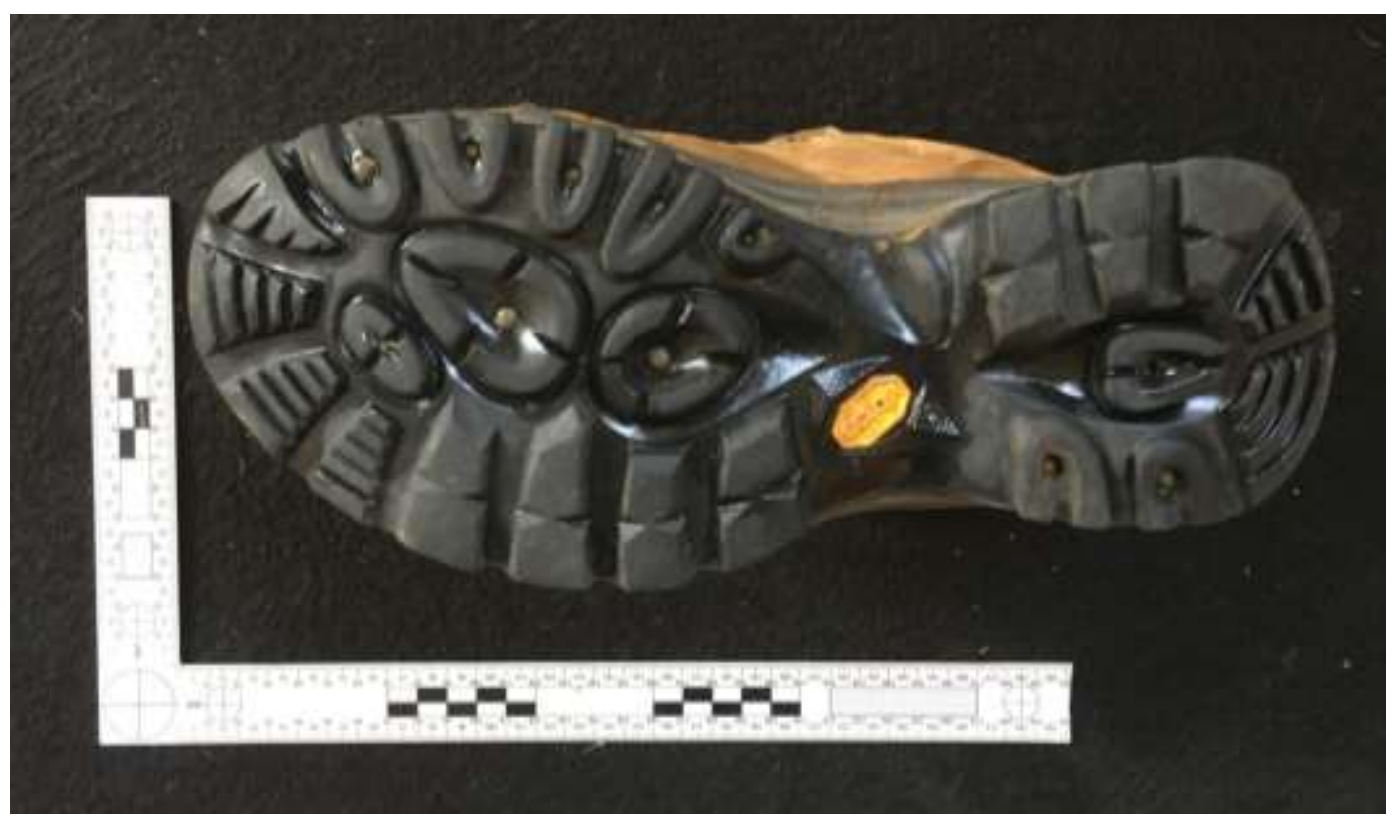

Figure 2. The design pattern of Vibram Vasque womens walking boot. The right shoe used within the study.

\subsection{Field Study}

To simulate a clandestine grave scenario, the variables of the study were produced within 60 small hand dug test pits, located within Cranfield University's F3 Forensic Fieldwork Facility (Figure 3). The soil within the facility consisted of loamy and clayey soils which were seasonally wet, slowly permeable, with a slightly acid but rich base [21].

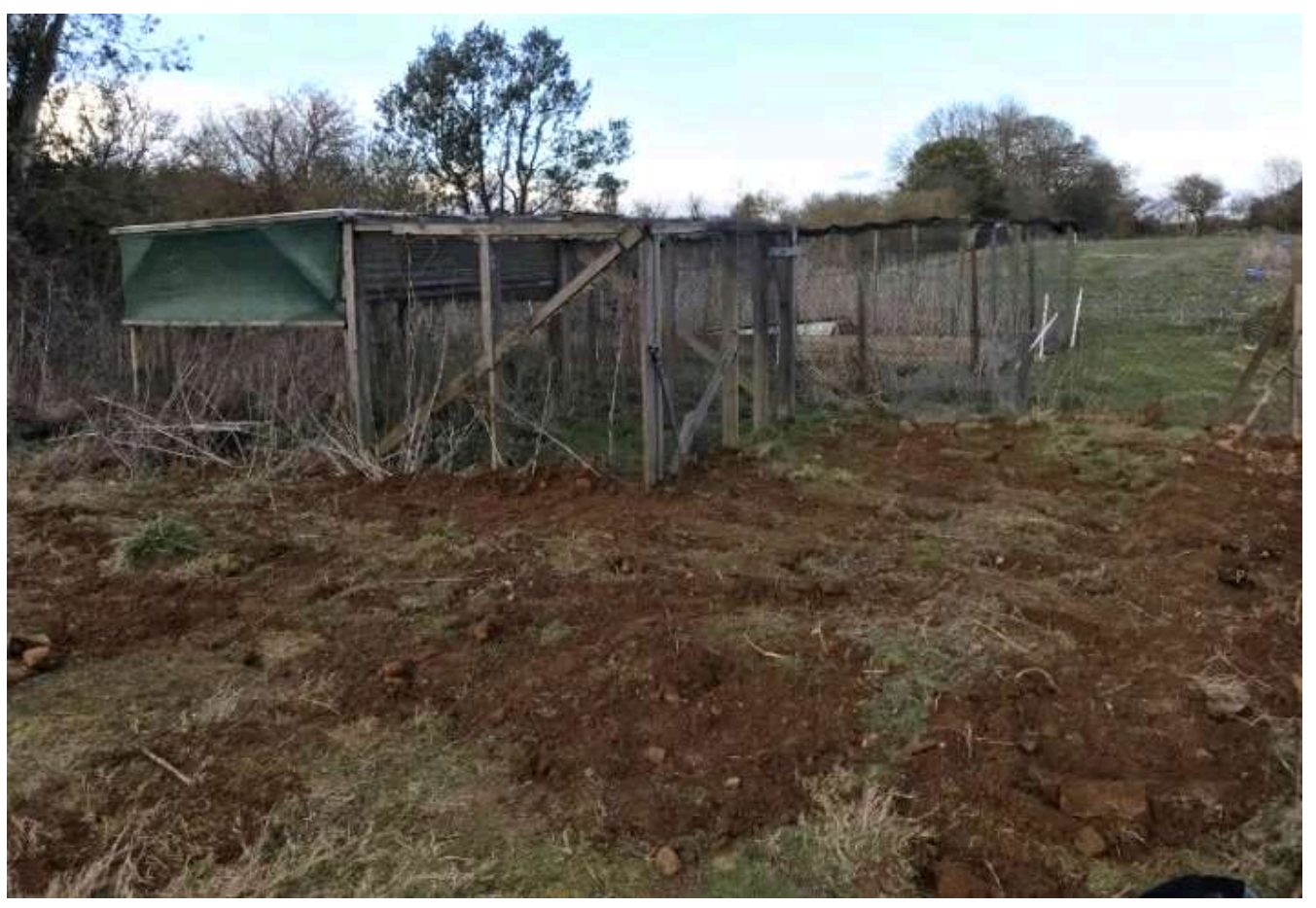

Figure 3. Cranfield University's F3 Forensic Fieldwork Facility. Photograph showing the Test Pits filled in with soil. 
Of the 60 test pits, 24 contained footwear impressions covered with $100 \%$ cotton shirts. The remaining 36 test pits contained footwear impressions which were not covered with clothing. The 36 noncovered footwear impressions were placed in test pits comprising of three different depths, $20 \mathrm{~cm}$, $30 \mathrm{~cm}$ and $40 \mathrm{~cm}$. Once backfilled with soil, the test pits were left for three prolonged time periods, 1 month, 2 months and 4 months. Table 1 outlines the combination of variables divided between the number of test pits. The same depths were replicated within the 24 test pits containing the footwear impressions covered with clothing; these depths were recovered at 1 month and 2 months (Table 2). Due to land and time constraints within the study, a 4-month clothing cover test could not be assessed.

Table 1. The number of test pits with no clothing cover within each variable.

\begin{tabular}{l|lcr}
$\begin{array}{l}\text { UNCOVERED } \\
\text { 36 TEST PITS }\end{array}$ & \multicolumn{1}{l}{ M MONTH } & 2 MONTHS & 4 MONTHS \\
\hline 20CM & 4 Test Pits & 4 Test Pits & 4 Test Pits \\
30CM & 4 Test Pits & 4 Test Pits & 4 Test Pits \\
40CM & 4 Test Pits & 4 Test Pits & 4 Test Pits
\end{tabular}

Table 2. The number of test pits with clothing cover within each variable.

\begin{tabular}{l|ll}
$\begin{array}{l}\text { COVERED } \\
\text { 24 TEST PITS }\end{array}$ & $\mathbf{1}$ MONTH & 2 MONTHS \\
\hline $\mathbf{2 0 C M}$ & 4 Test Pits & 4 Test Pits \\
30CM & 4 Test Pits & 4 Test Pits \\
40CM & 4 Test Pits & 4 Test Pits
\end{tabular}

The control footwear impressions were produced in a similar way to Farrugia et al study [22], by using a stamping motion with the right sided shoe, making sure the toe and heel both made contact with the soil substrate. The force was created and kept consistent by using researcher $M S$ to create all the known impressions. Each impression was photographed with an L' Shaped scale at a full right angle which encompassed the dimensions of the mark. This was achieved so the original condition of the footwear mark could be documented. Within the UK, footwear marks are photographed by crime scene investigators (CSI) with a scale to enable 1:1 footwear comparison in police footwear units [1]. The type of camera used was a Canon EOS 450D and was held perpendicular to the impression. The scale was placed on the same plane as the footwear mark within each slot, each time filling the frame. These conditions were replicated during the recovery phase of the study; each excavated slot was recorded only using photography. The graves were filled using its own backfill; the original soil, previously removed in the creation of the test pits.

The weather conditions throughout the study were uncontrollable and varied throughout the 4 months (March 2019 - July 2019), with a mixture of rain, overcast and dry periods. When producing 
the known footwear impressions within the test pits, the weather was mild with light to heavy showers throughout the day. For the recovery of the 1 month and 2-month non-covered footwear marks and the 1-month recovery of the covered impressions, the weather was mild with heavy rain with dry breaks. For the last recoveries of 4 months non-covered footwear marks and 2 months covered, the weather was very hot and dry.

Excavation tools used throughout the recovery phase of the study consisted of a spade, 4 inch pointing trowel, wooden clay modelling tools and a small brush. All test pits were excavated as single context excavations, where the soil within the test pit was removed, while keeping the original cut of the test pit preserved. As demonstrated by Evis et al's [17] study, this is a reliable technique when excavating forensic evidence, due to a higher consistency of mark recovery in comparison to arbitrary excavation. As the depths in this study were known, a spade was used to remove a large proportion of the soil before micro excavation techniques were employed using the smaller tools. These techniques included brushing loose soil away from the area of interest and very carefully removing the soil, small sections at a time.

\subsection{Characteristic Comparison Study.}

The recovery of footwear marks from crime scenes within the UK is outlined by the National Policing Improvement Agency (NPIA) within the Footwear Marks Recovery Manual [1]. The NPIA [1] state three gradings of evidential footwear marks; full, partial or fragmented. 2D prints were taken of the shoes sole pattern using the Bigfoot ID Identicator inkless shoe print kit. The prints produced were based upon the three aforementioned grading descriptions. Using the full 2D print of the sole pattern, class characteristic design patterns were grouped and counted for photographic comparison between the 3D footwear impressions placed within the test-pits, and any recovered excavated impressions (Figure 4). This demonstrated the design characteristics which could be replicated within the 3D impressions: a total of 26 . 

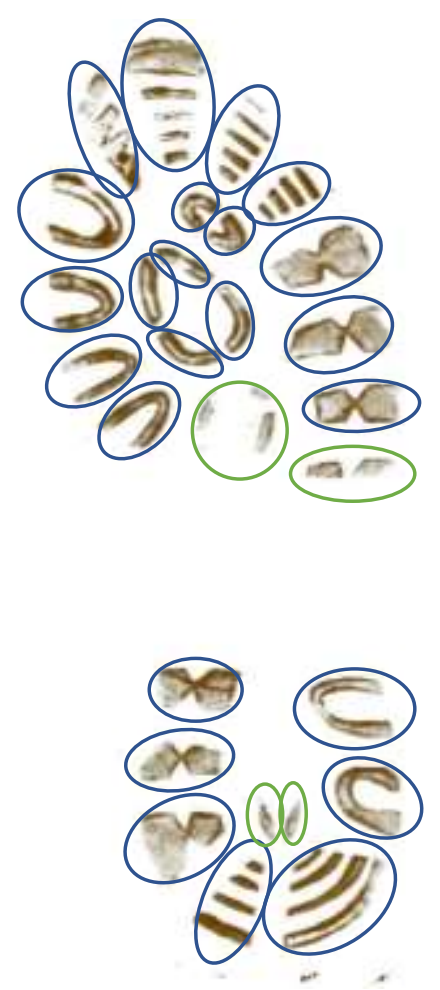

Figure 4. 2D print of the Vibram Vasque womens walking boot.

Blue circles show complete design patterns. Green circles show Incomplete design features.

Figure constructed by Author

The outer sole patterns chosen for comparison as they can be clearly observed. A grading system was developed by the authors to group the number of design pattern characteristics which were observed during recovery (Table 3; Figure 5). There is no universal grading system used in relation to design patterns because identification is based on the experience of the examiner, the distinctive characteristics, pattern, size and type of the footwear [6]. Therefore, a grading system was developed, adapted from NPIA guidelines [1, 6], for use in this study only and was based on the most complete impression placed within the test pits. The most complete 3D impression placed into the test pits, contained $74 \%$ of the 26 design characteristics counted on the full 2D print mark. Studies have shown that not every design pattern will be replicated when an impression is produced [1, 3]. To account for this within the grading system complete design features were weighted in comparison to patterns and shapes which were incomplete and only partially visible. Complete sections of the design pattern were counted as $\{1\}$, whereas incomplete sections were counted as $\{0.5\}$. These were weighted due to the larger evidential value of complete characteristics compared to incomplete [23]. 
Table 3. Footwear Quality Grading System. Unobservable 0 design characteristics visible. Poor 1.0 - 3.5 design characteristics visible, unknown which section of the outer sole these patterns are associated with. Minimal, $4.0-7.5$ design characteristics visible. 3: Sufficient, outline of footwear impression is visible, 8.0-11.5 design characteristics visible. 4: Good, clear outline of footwear impression, Mid sole, Toe and Heel sections of the outer sole are clearly visible within the impression, 12.0 - 15.5 design characteristics visible. 5: High, full impression visible, design characteristics are distinct, $16+$ design characteristics visible.

\begin{tabular}{ccc}
\hline Grade & Description & $\begin{array}{c}\text { Number of Design Pattern } \\
\text { Characteristics }\end{array}$ \\
\hline 0 & Unobservable & 0 \\
1 & Poor & $0.5-3.5$ \\
2 & Minimal & $4.0-7.5$ \\
3 & Sufficient & $8.0-11.5$ \\
4 & Good & $12.0-15.5$ \\
5 & High & $16.0+$
\end{tabular}
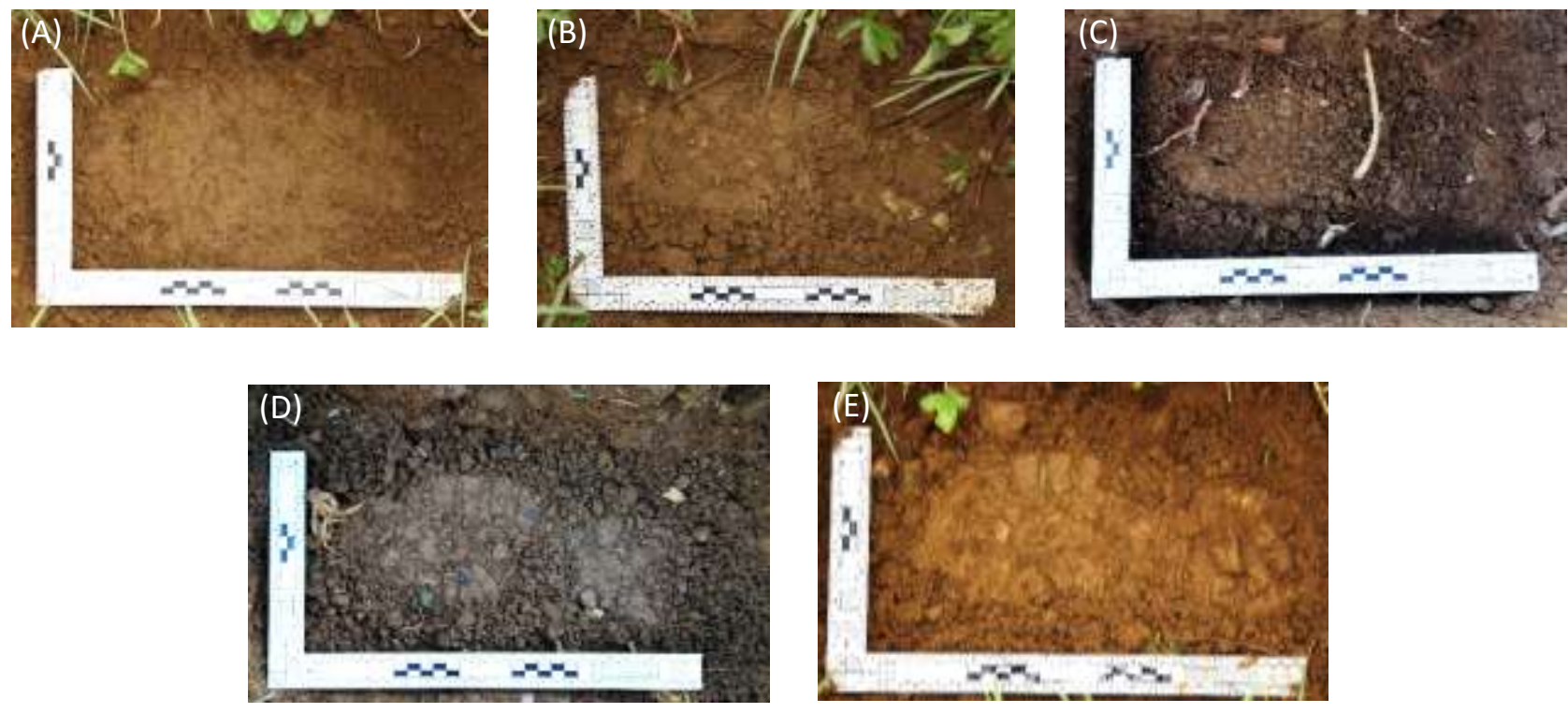

Figure 5. Visual representation of each grade within the grading system.

(A) 1: Poor, 1.0 - 3.5 design characteristics visible, unknown which section of the outer sole these patterns are associated with. (B) 2: Minimal, 4.0 - 7.5 design characteristics visible. (C) 3: Sufficient, outline of footwear impression is visible, $8.0-11.5$ design characteristics visible. (D) 4: Good, clear outline of footwear impression, Mid sole, Toe and Heel sections of the outer sole are clearly visible within the impression, 12.0 - 15.5 design characteristics visible. (E) 5: High, full impression visible, design characteristics are distinct, 16+ design characteristics visible.

The number of design characteristics were counted using the photographs taken during the deposit and recovery of the impressions within the test pits. The known footwear impressions, which were produced originally within the test pits, were first compared to the $2 \mathrm{D}$ print to count how many class design pattern characteristics were originally present before soil backfilling. The photographs of the excavated recovered marks were then compared to the photographs taken of the original marks and the number of complete and incomplete design patterns were counted. The number of design 
characteristics were then cross referenced to the grading system. This produced grading values from $0-5$. Casting was not used within the study for the comparison of impressions, due to the damage it would cause to the marks prior to burial [24].

Three-way ANOVA analysis was selected to test the effects and interactions of depth, time and cover on the difference between the number of design characteristics observed in the test pits initially and after excavation. $R$ (version 3.5.1) software was used at a significance value of 0.05 [25].

\section{Results}

Out of the 60 test pits, 59 were successfully excavated and were photographed and documented for analysis. Out of the 36 test pits containing footwear marks not covered by clothing, $36.1 \%$ contained marks which could be recovered. When the number of design characteristics were cross referenced against the grading system (Table 4 ), $63.9 \%$ of the test pits were graded as Unobservable (0), $27.8 \%$ were graded as Poor ( $1 ; 1.0$-3.9 characteristics; Figure 6$)$ and $8.3 \%$ graded as Minimal $(2 ; 4.0-7.9$ characteristics; Figure 7.). None of the test pits contained recoverable marks graded Sufficient $(3 ; 8.0$ - 11.9 characteristics) or above. It should be noted that the original footwear mark that was placed into these test pits was not a full mark. Therefore, Table 5 outlines the grading scores of the original marks produced within the test pits against the graded excavated marks.

Table 4. Distribution of graded footwear marks (\%) by clothing.

\begin{tabular}{l|ll} 
GRADING & NO CLOTHING COVER & CLOTHING COVER \\
\hline $\mathbf{0}$ & $63.9 \%$ & $4.4 \%$ \\
$\mathbf{1}$ & $27.8 \%$ & $34.8 \%$ \\
$\mathbf{2}$ & $8.3 \%$ & $39.1 \%$ \\
$\mathbf{3}$ & Unobserved & $21.7 \%$ \\
$\mathbf{4}$ & Unobserved & Unobserved
\end{tabular}




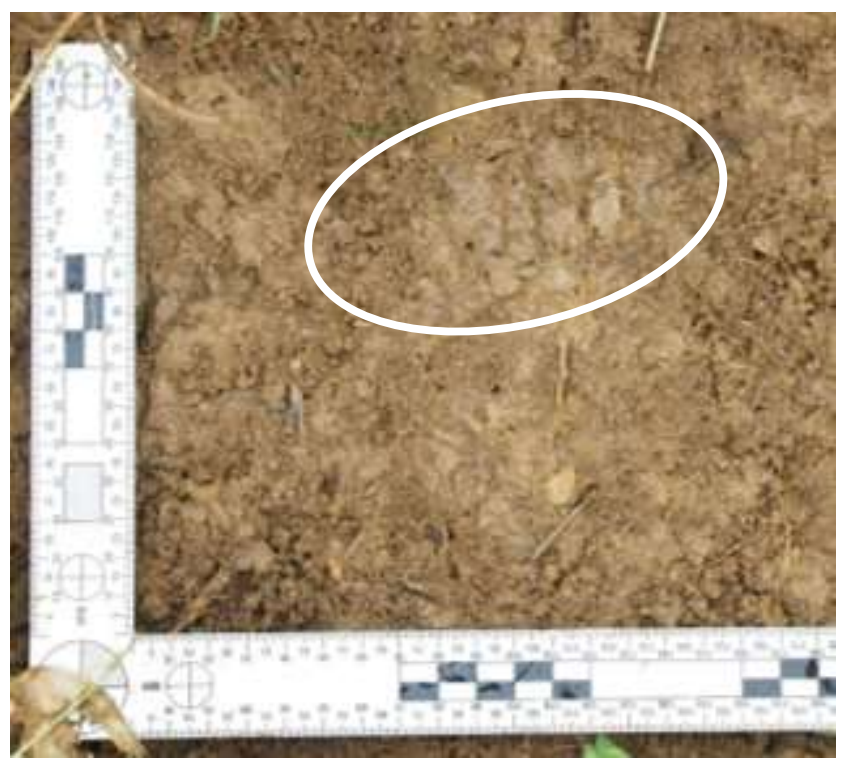

Figure 6. An excavated footwear mark graded as poor. The white circle highlights the marks visible. Number of complete design characteristics: 2; Number of Incomplete design characteristics: 3

Variables: no clothing cover, 2 months and $20 \mathrm{~cm}$ Photo has been cropped.

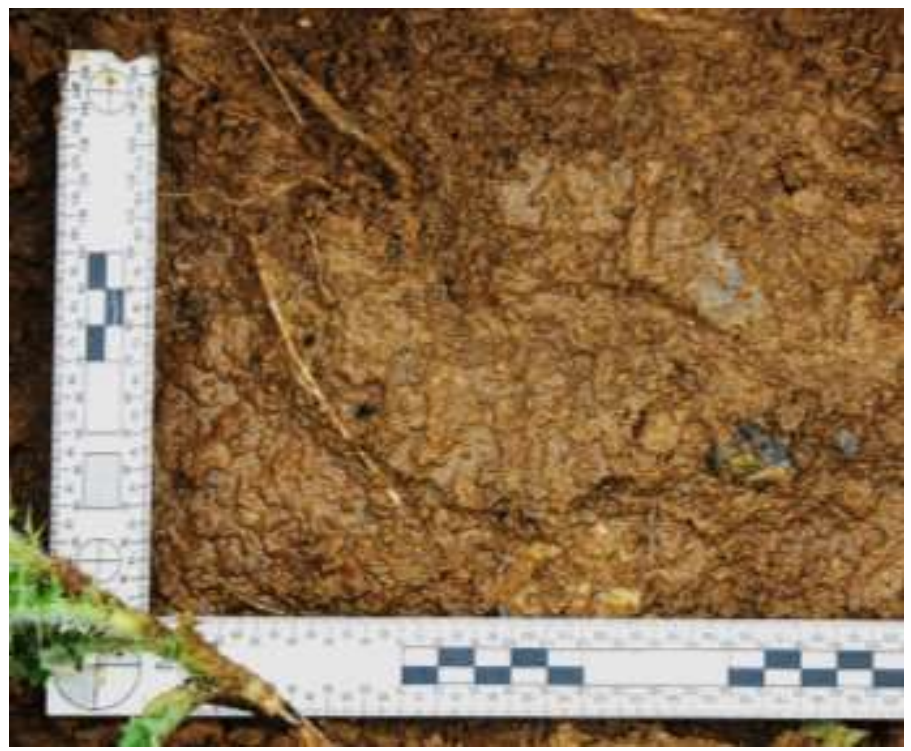

Figure 7. An excavated footwear mark graded as minimal. Complete and incomplete design patterns visible in the mid sole section.

Number of complete design characteristics: 6; Number of Incomplete design characteristics: 3Variables: no clothing cover, 2 months and $20 \mathrm{~cm}$ Photo has been cropped. 
Out of the 23 excavated test pits containing footwear marks covered with clothing, $95.7 \%$ had recoverable footwear marks. When the number of characteristics were placed within the grading system, $34.8 \%$ of the test pits contained marks which were graded as poor (Figure 8 ), $39.1 \%$ were graded as minimal and $21.7 \%$ were graded as sufficient (Figure 9). Only 1 test pit contained a mark which was unobservable; when excavating this grave it had become apparent that the t-shirt placed within the test pit had been disturbed and was no longer there. The cause of is disturbance is unknown.

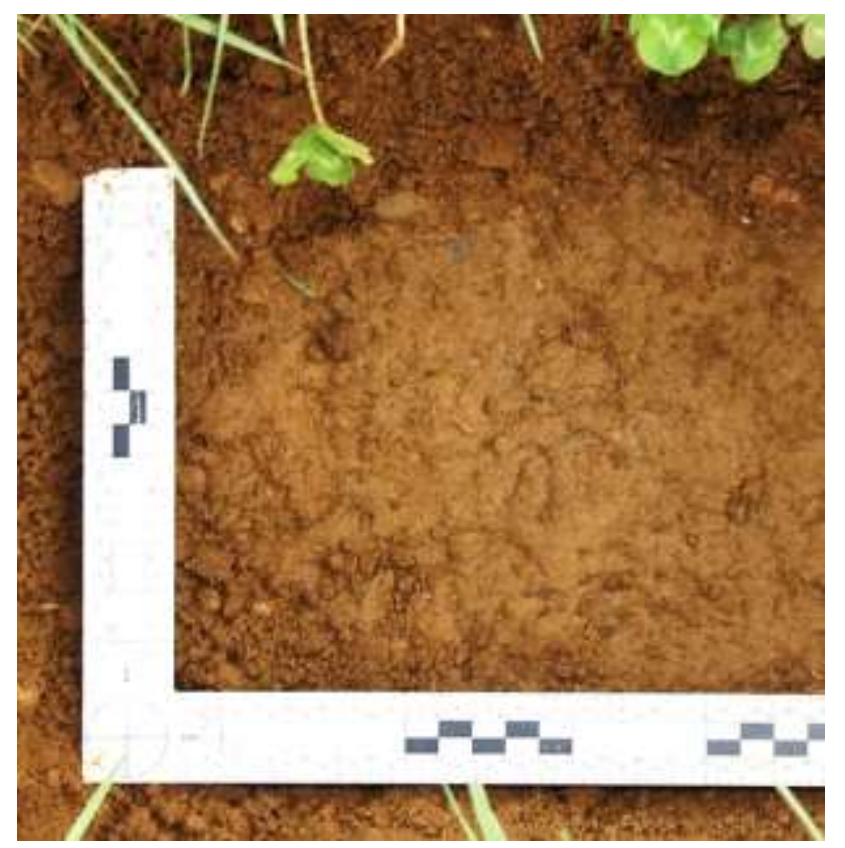

Figure 8. An excavated footwear mark graded as poor. Complete hollow semi-circle design patterns are visible. Number of complete design characteristics: 2; Number of Incomplete design characteristics: 2

Variables: clothing cover, 1 month and $30 \mathrm{~cm}$ Photo has been cropped. 


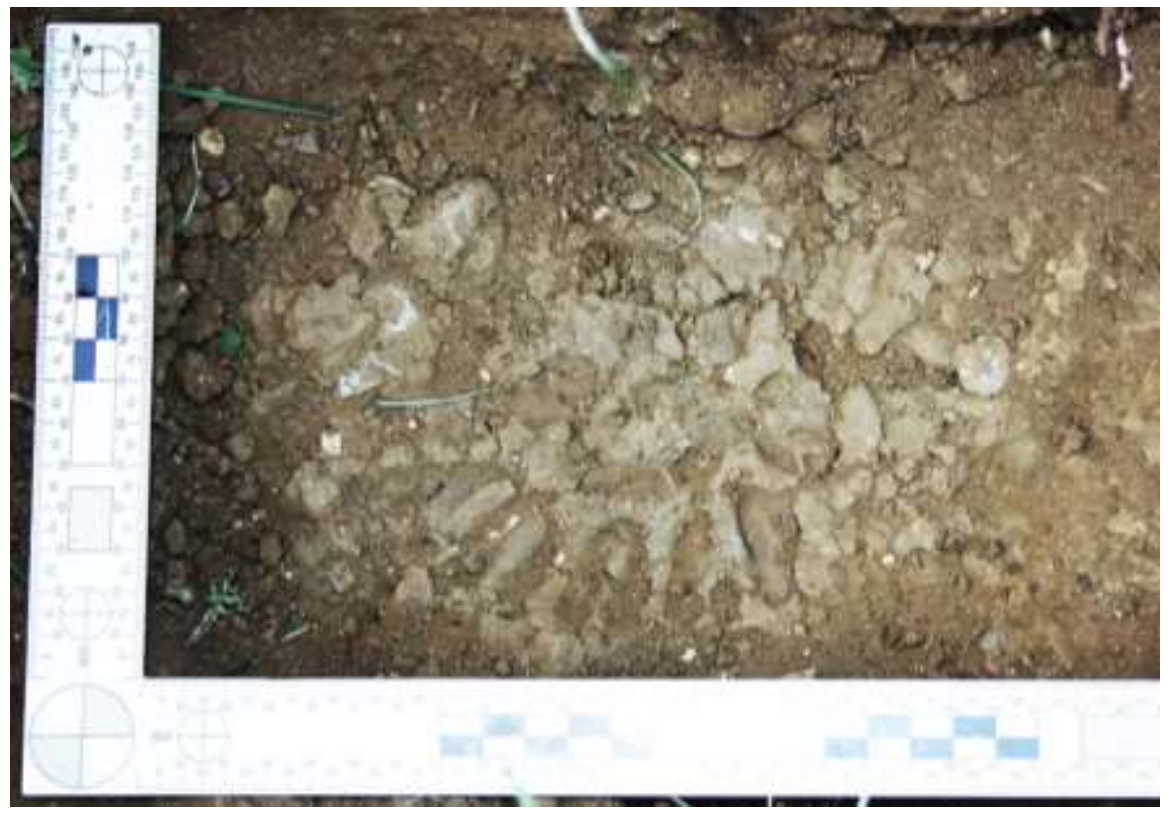

Figure 9. An excavated footwear mark graded as sufficient. Outline and design patterns are clearly visible from the midsole section.

Number of complete design characteristics: 7; Number of Incomplete design characteristics: 4 Variables: clothing cover, 2 months and $30 \mathrm{~cm}$

Photo has been cropped.

None of the 59 test pits contained excavated marks which could be graded as either good $(4 ; 12.0-$ 15.9 characteristics) or high $(5 ; 16.0+$ characteristics $)$. The mid sole and the toe of the outer-sole were most frequently observed within the marks placed into the test pits and the marks being recovered. The heel section of the sole was observed infrequently during recovery, even if the section was clear within the originally produced mark. The majority of characteristics recovered were part of the midsole section. Some design details which were observable within the 2D prints were not replicated within every 3D impression. This included the curved line pattern within the toe section and was replicated less than the hollow semi-circle features in the mid sole. No insole section of the outer sole was replicated either on the 2D print or within the 3D impressions.

\subsection{Time}

At 1-month recovery, of the 12 test pits excavated without clothing, $50 \%$ contained marks which could be recovered, whereas, of the 11 test pits excavated containing clothing, $100 \%$ of the test pits contained marks. Table 6 and Figure 10 outlines the percentage of test pits within each grading category. The data for gradings 4 (good) and 5 (high) are not represented in Table 6 or Figure 10 due to the absence of the covered or uncovered test pits containing recovered marks of these gradings. At 2-months, $91.6 \%$ of the 12 excavated test pits with clothing contained recoverable marks. Within the 12 test pits without clothing cover, $58.3 \%$ of the marks were unobservable, $33.3 \%$ were graded as poor and one test pit contained a mark which was graded as minimal. Of the 12 test pits, with no clothing cover, excavated at 4 -months, $16.6 \%$ of the test pits contained recoverable marks. The 4 month recovery produced the least amount of observable design characteristics / footwear marks. 
Table6. Distribution of graded footwear marks (\%) by clothing and time.

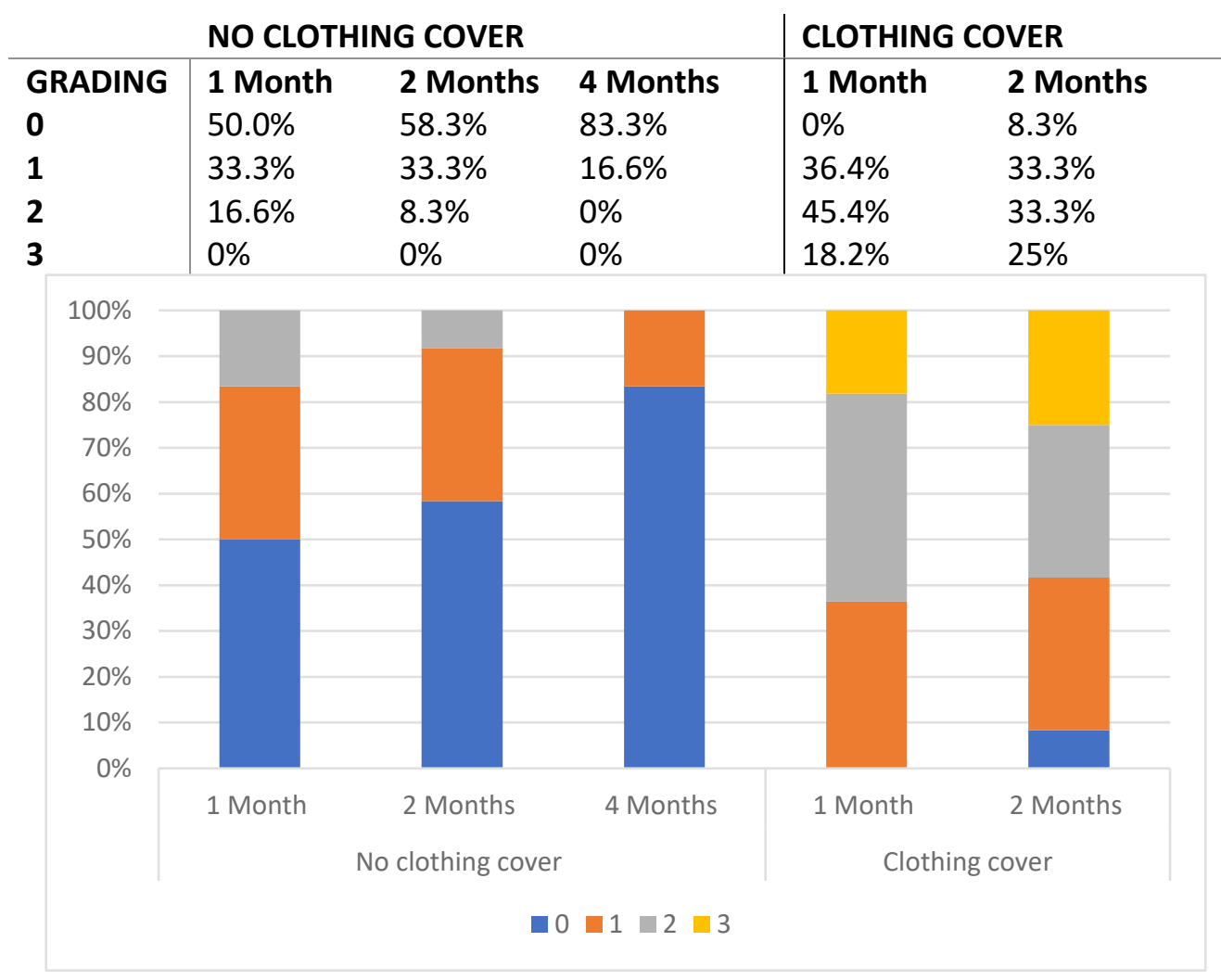

Figure 10. Stacked Column Graph showing the Distribution (\%) of graded footwear marks by clothing and time. Grades included are 0 (Unobservable), 1 (Poor), 2 (Minimal), 3 (Sufficient).

\subsection{Depth}

Within the test pits containing footwear marks which were uncovered, $50 \%$ of the $20 \mathrm{~cm}$ depth had recoverable marks. The depth of $30 \mathrm{~cm}$ had $41.6 \%$ of marks recovered and the $40 \mathrm{~cm}$ depth had $16.6 \%$ recovered. Within the test pits containing clothing cover, $100 \%$ of the excavated $20 \mathrm{~cm}$ depth contained recoverable marks. The same result occurred at the $30 \mathrm{~cm}$ depth, while the $40 \mathrm{~cm}$ contained $87.5 \%$ of the recoverable marks, due to one test pit which was graded as unobservable. Table7 and Figure 11 outlines the percentage of test pits within each footwear grading category. The data for gradings 4 (good) and 5 (high) are not represented in Table7 and Figure 11 due to the absence of the covered or uncovered test pits containing recovered marks of these gradings.

Table7. Distribution of graded footwear marks (\%) by clothing and depth.

\begin{tabular}{l|lll|lll}
\multicolumn{5}{c}{ NO CLOTHING COVER } & & \multicolumn{3}{l}{ CLOTHING COVER } \\
\hline GRADING & $\mathbf{2 0} \mathbf{c m}$ & $\mathbf{3 0} \mathbf{c m}$ & $\mathbf{4 0} \mathbf{c m}$ & $\mathbf{2 0} \mathbf{c m}$ & $\mathbf{3 0} \mathbf{c m}$ & $\mathbf{4 0} \mathbf{c m}$ \\
$\mathbf{0}$ & $50.0 \%$ & $58.3 \%$ & $83.3 \%$ & $0 \%$ & $0 \%$ & $12.5 \%$ \\
$\mathbf{1}$ & $33.3 \%$ & $33.3 \%$ & $16.6 \%$ & $57.1 \%$ & $25 \%$ & $12.5 \%$ \\
$\mathbf{2}$ & $16.6 \%$ & $8.3 \%$ & $0 \%$ & $42.9 \%$ & $25 \%$ & $50 \%$
\end{tabular}




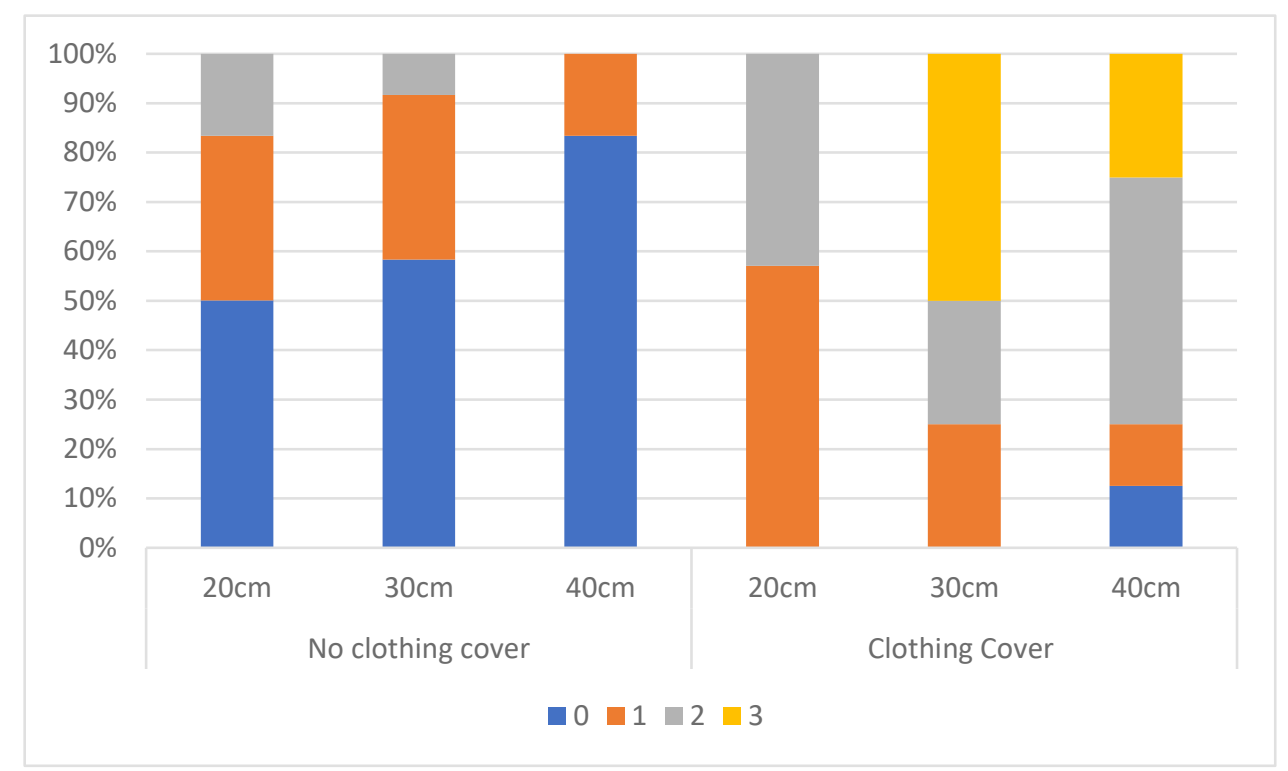

Figure 11. Stacked Column Graph showing the Distribution (\%) graded footwear marks by clothing and depth. Grades included are 0 (Unobservable), 1 (Poor), 2 (Minimal), 3 (Sufficient).

\subsection{Statistical Analysis.}

The standard way to analyse results of this type is 3-way ANOVA, with the response variable being the difference between the number of marks observed in the test pits initially and after excavation. Figure 12 shows that there is substantial within-cell variation for this response and suggests that Cover may have an effect, with covered cases showing smaller differences between original and excavated.

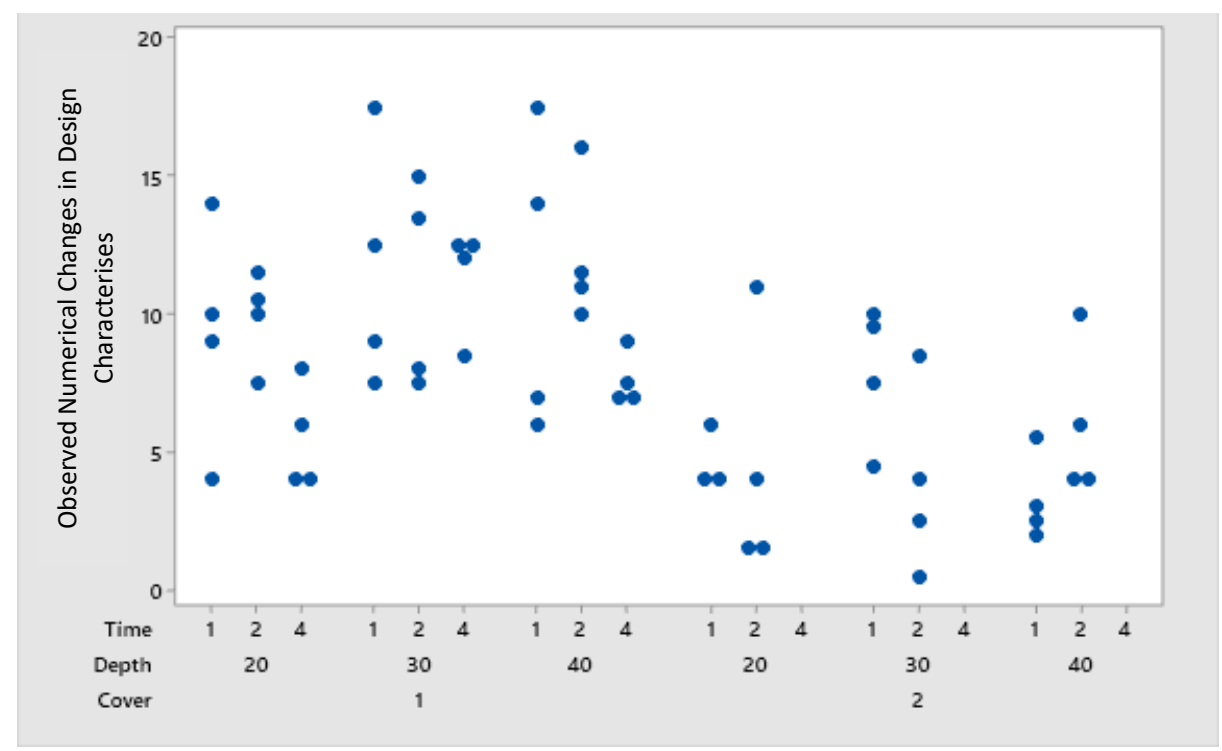

Figure 12. Individual Value Plot of Observed Numerical Changes in Pattern Characteristics Time: Months; Depth: cm; Cover: 1, No Clothing cover. 2, Clothing cover. Created by author in MiniTab19 Software 
The design is unbalanced because the 12 observations for 4 months with clothing cover could not be run, while one data point was missing, so that the 3-way interaction and the 2-way depth/time interaction terms cannot be estimated fully and the tests for the different main and interaction effects are not independent. Hence a standard backwards elimination approach was used, fitting successive models with fewer terms, removing the interactions first, and comparing the models with $\mathrm{F}$ tests. All analysis used the Im function of the $\mathrm{R}$ software package and standard model checking of residuals showed that the usual assumptions of normality and constant variance are reasonable in all cases.

This showed no evidence of a 3-way interaction ( $p>0.1)$, while whatever the order in which the 2-way interaction terms were removed there was no evidence of any 2-way interactions ( $p>0.1$ for all tests). Continuing to the main effects, Depth and Time were both not quite statistically significant, being just over the usual $5 \%$ level $(p>0.05)$, while Clothing is statistically significant $\left(p<10^{\wedge}-6\right)$. Hence the ANOVA table for main effects only is given in Table 8, with Depth and Time retained in the model as they are of direct interest and are borderline significant. From the main effects model the effect size for Clothing is 5.84 ( $\mathrm{SE}=0.93$ ), i.e. the difference in number of marks between original and recovered is on average 5.84 lower in covered pits.

Table8. Analysis of Variance for Main Effects Model

\begin{tabular}{lrrrrr} 
Response: & \multicolumn{6}{c}{ Difference } \\
\hline \multicolumn{1}{c}{ Source } & \multicolumn{1}{c}{ DF } & Sum Sq & Mean Sq & F-Value & P \\
\hline Cover & 1 & 337.09 & 337.09 & 33.08 & 4.482 \\
Depth & 2 & 57.93 & 28.96 & 2.84 & 0.067 \\
Time & 2 & 56.90 & 28.45 & 2.79 & 0.070 \\
Residuals & 53 & 540.02 & 10.19 & &
\end{tabular}




\section{Discussion}

Hunter and Cox [14] strongly emphasise the possibility that footwear impressions can lie underneath human remains within graves. The aim of this study was to assess the feasibility of recovering footwear marks from graves. To achieve this aim, objectives were created focussing on three conditions, the depth of the grave, the duration of burial and whether the presence of clothing covering the impressions will affect recovery. This study has demonstrated that the preservation and recovery of footwear impressions within graves is feasible.

Varying time periods of burial were incorporated into this study, due to the unfamiliarity of how time could impact the recovery of buried footwear mark impressions $[15,16]$. This study found that time did not have a significant impact on the recovery of footwear marks from graves. This result is unsurprising as archaeological studies have demonstrated that human footprint impressions of a prehistoric age can be recovered from coastal sites around the UK [26]. It is possible the preservation is due to the type of substrate teamed with the fact that pre-historic footprint sites within the UK are generally preserved, due to the mixture of coastal sediments such as silty clay [26]. This study was produced within a similar substrate of loamy and clayey soils. If the soft surface is unstable, then the footwear impressions will only be held for a short amount of time and it is a possibility that the impression will not hold the characteristics which are required for identification [1].

The most significant variable affecting the recovery of footwear marks from graves was cover. The results indicate that covering footwear marks with clothing is important. $95.7 \%$ of the test pits with clothing, contained recoverable footwear marks, compared to $36.1 \%$ of those without. The preservation and number of characteristics observed within the excavated marks also scored higher within the grading system in the test pits containing clothing, than those without. $22 \%$ of the test pits with clothing were graded as sufficient, whereas the highest grading of the test pits without clothing was minimal (8\%). The results indicate that footwear marks which have been covered by material, are more likely to be recovered than those which are not. Even though, the gradings of the footwear marks after recover were sufficient or below, partial impressions are of evidential significance and can be used for forensic comparisons [1]. The significance of covering of a footwear mark is supported by Hunter and Cox [14], where the published photograph of a footwear mark was found was under a body. It can be suggested that recovery is more feasible when marks are covered due to the way the grave is excavated. When there is a visual marker for the potential bottom of the grave, such as a body, excavation becomes increasingly more delicate. The authors found that while excavating the test pits containing clothing, they were able to distinguish the location of the mark more accurately due to the visual indicator of clothing. This meant that more destructive techniques such as using the spade and heavy trowelling, were stopped sooner than in the test pits were there was no visual indicators at the bottom of the test pit. However, it is important to note, that even though there was no visual indicator within the test pits containing footwear impressions which had not been covered, marks were still recovered due to delicate and precise excavation in conjunction with the recoveree's experience.

It needs to be noted that a footwear mark covered with just material will have a different impact to a footwear mark which has been covered by a body. It is currently unknown how the process of decomposition would have an impact on a soil impression. The likely hood of successful preservation would also depend on the position of the body on top of the mark. The impression is more likely to be 
preserved under body parts which do not have a heavy impact on the ground, such as under knees or necks. On the other hand, depth was not demonstrated to be statistically significant in the recovery of footwear marks. It could be argued that more soil on top of a mark is also an increase in weight. However, a 4month recovery with clothing was not achieved and therefore, further investigation into the effects of weight on the recovery of footwear marks is recommended.

The depth of the test pit was not statistically significant, being just over the usual $5 \%$ level ( $p>0.05)$. The results showed that there was a higher percentage of marks recovered within the $20 \mathrm{~cm}$ and $30 \mathrm{~cm}$ depths compared to the $40 \mathrm{~cm}$ depths. Hochrein's [15] studies suggested that the increased depth of a grave could be affected by ground water activity and rodent disturbances. Possible rodent disturbances could explain the disappearance of the clothing within one of the test pits at $40 \mathrm{~cm}$ as a field mouse was disturbed during the creation of the test pits, verifying their presence in the area and at that depth. The impacts related to an increased grave depth could suggest why there was a lower percentage of marks recovered within the deeper test pits. It is suggested that further investigation would be needed to test this hypothesis.

Overall, this study demonstrates that a high proportion of footwear marks graded within the lower boundaries of the grading system (0-2) were recovered. For example, in the non- clothing cover test pits only $36.2 \%$ contained recoverable marks which were either graded as poor or minimal. Nevertheless, Bodziak, [3] clearly states that complete footwear marks are not needed for the comparison of footwear and that if detailed characteristics are present then the mark can still be significant, even if incomplete. There is also currently no established set number of characteristics needed for positive identification. Within the UK, the Crown Prosecution Service (CPS) [27] states that footwear evidence is based on the examiners experience rather than a mathematical formula which will produce a likelihood ratio. The establishment of a set number of characteristics needed for positive identification has been previously discussed, but has never amounted to anything [23]. This reiterates the need to recover any mark, no matter how incomplete because important information gathered from an impression may not be apparent at the crime scene and may only be discovered when the impression is analysed [23]. The delicate nature of incomplete marks demonstrates the importance of extreme vigilance when excavating and lifting the material or body from a grave, due to the potential for footwear marks to be recovered underneath.

Although the 60 test pits demonstrated a variation in quality between the known impressions produced, this was expected as 3D impressions produce greater variation between individual impressions. This is due to the loose nature of soil types, because of surfaces succumbing to the shift in weight occurring when the impression is made [28]. The statistical analysis was based on differences in design characteristics between the footwear marks, placed into the test pit and the mark which were excavated. Even with a variation between impressions, cover still has imperative importance in relation to recovery.

Finally, although this study only focused on the observation of design patterns, it has demonstrated that these can be preserved when buried. The authors advise that vigilant excavation is undertaken by Forensic Archaeologists and the use of small excavation implements, such as wooden clay modelling tools and a small brush are needed for recovery of footwear marks. This in turn can reduce the amount of damage to marks and increase recovery of detailed characteristics. The potential for intelligence that links footwear and marks recovered from crime scenes are based on distinctive characteristics, damage and wear, pattern, size and type of the footwear [6]. This study obtained this crucial information from the footwear marks. 


\section{Conclusion}

Overall, this study has demonstrated that footwear marks can be recovered from graves. The most significant variables affecting the feasibility of footwear recovery was cover followed by depth. Time did not have a statistical significance on the recovery, possibly due to the nature of the clayey substrate used within the study. The cover variable shows significant importance into the feasibility of recovering footwear marks from graves. $96 \%$ of the test pits with clothing contained recoverable marks, compared to $36 \%$ of those without. The recovered marks within the clothing cover test pits also scored higher within the grading system developed for this study. This study has recognised that careful consideration and vigilant excavation skills are needed when excavating graves in relation to the recovery of footwear marks, as the study has demonstrated that footwear mark recovery is possible from such conditions. The recovery of potential footwear marks within graves may assist in providing crucial intelligence on the perpetrator. It is recommended that the forensic practitioner locating and collecting these footwear marks are aware of factors influencing their presence and detail to allow for successful recovery.

\section{Further recommendations}

Although this study has demonstrated that the recovery of footwear marks is feasible, further research should be carried out to assess the impact of soil types. It is known that clayey soils are more likely to hold impressions for a long duration of time, however there is the need for a study to assess how different soil types, such as sandy and silty soils can hold buried impressions. It is also recommended that this study should be replicated using different footwear styles and different levels of individual characteristics present on the outer sole of the footwear. This approach will allow for an increased understanding of the level and quality of detail it is possible to recover. Finally, this study was also based in south- west of England (within a regional climate). The impact of weather could be studied within different climates to assess any significance on the recovery of footwear marks from graves.

\section{Funding}

This research did not receive any specific grant from funding agencies in the public, commercial, or not-for-profit sectors. 


\section{References}

1. National Policing Improvement Agency (NPIA). Footwear marks recovery manual. http://library.college.police.uk/docs/appref/NPIA-(2007)-Footwear-Marks-Recovery-Manual.pdf , 2007 (Accessed: 08 May 2019)

2. D. Baldwin, C. O'Mahoney, 2016. 6. Marks and Impressions, in: P. White (Eds), Crime Scene to Court: The Essentials of Forensic Science. 4th ed. The Royal Society of Chemistry., Cambridge, 2016.

3. W.J. Bodziak, Forensic Footwear Evidence, Taylor \& Francis Group., Florida, 2017

4. A.R.W. Jackson, J.M. Jackson, Forensic Science. $4^{\text {th }}$ ed. Pearson Education Limited., Harlow, 2017

5. M.R. Bennett, D. Huddart, S. Gonzalez, Preservation and Analysis of Three-Dimensional Footwear Evidence in Soils: The Application of Optical Laser Scanning, in: K. Ritz, L. Dawson, D. Miller (eds) Criminal and Environmental Soil Forensics. Springer., Dordrecht, 2009

6. National Policing Improvement Agency (NPIA), 2012. Forensic Submissions: Good Practice Guide. http://library.college.police.uk/docs/appref/NPIA-(2012)-Forensic-Submissions-Good-PracticeGuideV5.pdf. 2012 (Accessed: 29 July 2019)

7. J. M. Brooks, Identifying and Sharing Class Characteristics of Outsole Impressions. Journal of Forensic Identification, 56 (2006) 737-743.

8. College of Policing, 2018. Investigation: Forensics: Footwear, https://www.app.college.police.uk/app-content/investigations/forensics/\#top. 2018 (Accessed: 29 July 2019)

9. D. Beaufort-Moore, T. Cook, Crime Scene Management and Evidence Recovery. $2^{\text {nd }}$ ed. Oxford University Press., Oxford, 2015

10. W.J. Bodziak, L. Hammer, G.M. Johnson, R. Schenck, Determining the Significance of Outsole Wear Characteristics During the Forensic Examination of Footwear Impression Evidence. Journal of Forensic Identification 254/ 63 (2012) 254-278

11. M.B. Smith, The Forensic Analysis of Footwear Impression Evidence. Forensic Science Communications. V 11, No. 3 (2009)

12. G. MacKinnon, K. Harrison, Forensic Anthropology and Archaeology in the United Kingdom, in: S. Blau, D.H. Ubelaker, Handbook of forensic anthropology and archaeology. $2^{\text {nd }}$ ed. Routledge., Abingdon, 2016

13. T. Coyle, 5: Trace and Contact Evidence, in: P. White, Crime Scene to Court: The Essentials of Forensic Science. 4th ed. The Royal Society of Chemistry., Cambridge, 2016

14. J. Hunter, M. Cox, Forensic Archaeology: advances in theory and practice. Routledge., Oxon, 2005

15. M. Hochrein, The Dirty Dozen: The Recognition and Collection of Toolmarks in the Forensic Geotaphonomic Record. Journal of Forensic Identification, 47 (1997) 171-198.

16. M.D. Clark, Toolmark Identification of a Mattock to a Clod of Soil from a Grave. Journal of Forensic Sciences, 54 (2011) 241- 243 
17. L.H. Evis, I. Hanson, P.H. Cheetham, An experimental study of two grave excavation methods: Arbitrary Level Excavation and Stratigraphic Excavation, STAR: Science \& Technology of Archaeological Research. (2016) 1- 15.

18. J. Hunter, C. Roberts, A. Martin, Studies in Crime: An introduction to forensic archaeology. Routledge., Abingdon, 2002

19. L.L. Menez, The place of a forensic archaeologist at a crime scene involving a buried body. Forensic Science International, 152 (2005) 311-315

20. C.S. DeFrance T.Y. Payne, Location, Recovery, and Metamorphosis of Snow Impressions Hidden Beneath Subsequent Snowfall. J Assoc Crime Scene Reconstr 21 (2017) 15-27

21. Cranfield Soil and Agrifood Institute, Soilscapes. http://www.landis.org.uk/soilscapes/\# 2019, (Accessed: 21 August 2019)

22. K.J. Farrugia, K.A. Savage, H. Bandey, N.N. NicDaéid, Controlling the variable of pressure in the production of test footwear impressions. Science and Justice 52 (2012) 168-176

23. D.S. Hilderbrand, Four basic components of a successful footwear examination. Journal of Forensic Identification, 49 (1999) 37-59.

24. T.J.U. Thompson, P. Norris, A new method for the recovery and evidential comparison of footwear impressions using 3D structured light scanning. Science \& Justice, 58 (2018) 237-243.

25. R Core Team. R: A language and environment for statistical computing. R Foundation for Statistical Computing, Vienna, Austria. URL https://www.R-project.org/. 2018, (Accessed: 08 April 2020)

26. M.R. Bennett, S. Gonzalez, D. Huddart, J. Kirby, E. Toole, Probable Neolithic footprints preserved in inter-tidal peat at Kenfig, South Wales (UK). Proceedings of the Geologists' Association 121, 1 (2010) 66-76.

27. The Crown Prosecution Service (CPS). 2017. Identification: Identification by Fingerprints and Footwear Impressions (Code D, Para 4). https://www.cps.gov.uk/legal-guidance/identification. 2017 (Accessed: 12 August 2019)

28. W. Bodziak, Footwear impression evidence. 2nd ed. CRC Press., Boca Raton, 2000. 